\title{
Analysis of Temperatures in the Cold Storage of Finished Products
}

\author{
Gabriela Bogdanovská', Beáta Stehlíková', Ján Kačur* \\ 1 Technical University of Košice, Faculty BERG, Institute of Control and Informatization of Production Processes, \\ Němcovej 3, 04200 Košice, Slovak Republic \\ * Corresponding author's e-mail: jan.kacur@tuke.sk
}

\begin{abstract}
The analysis of temperatures in the cold store of finished products was performed due to the occurrence of temperature fluctuations. The analysis in the report was conducted using Kruskal-Wallis test, Bartlett test, Nemenyi's test Statistical analysis of measured values in individual months. The relationship between the temperature in the cold store and the outside air temperature was investigated. Quality tools were also used in the thesis. The causes of temperature fluctuations were determined by Cause-Effect diagnostics. The relationship between the main causes was analyzed with Relation Diagram. Corrective measures were then determined to minimize the temperature fluctuations in the cold store.
\end{abstract}

Keywords: cold storage warehouse, temperature monitoring, temperature fluctuations, statistical evaluation, Kruskal-Wallis test, Bartlett test, Nemenyi's test.

\section{INTRODUCTION}

Temperature is one of the most important factors affecting the wholesomeness of foodstuffs. In the framework of legislative requirements, the operators of cold and refrigerating stores must monitor the temperature. The temperature monitoring must be carried out using a thermometer that will allow the recording of highest and lowest temperatures over a period of time. The temperature fluctuations can cause degradation of food.

A lot of cold store operators use low-cost thermometers, while others use radio frequency identification (RFID) for temperature monitoring and inventory monitoring. RFID technology passively records temperature data and translates temperature data into readily-available data within inventory management systems. This allows a complete tracking of the plant without any additional labor costs incurred in the case of manual readout.

After completing the demand forecast, operators can make decisions about the use of storage areas in temperature zones. The temperature mapping is especially essential for the facilities working with sensitive products such as food products or pharmaceuticals. Mapping is performed to verify the efficiency of storage conditions in refrigerated / cool warehouses and refrigerators. In these devices, it is necessary to monitor the changes in the temperature occurring in the vicinity of the fan due to the opening the doors, the movement of the persons and the number of products in time. Temperature mapping identifies the points with the highest temperature fluctuations and temperature differences as well as enables to analyze their causes. Temperature mapping can be influenced by external factors such as weather, but also internal ones, such as airflow limitations. When the mapping process is completed, temperature sensors should be installed to allow continuous monitoring of the areas most affected by temperature changes. The process of temperature mapping should be planned and documented. Before installing sensors, it is necessary to develop documentation that must be approved and reviewed by process owners and quality auditors.

While planning the layout of the monitoring system, the relevant country legislation must be taken into account. The recommended 
number of is to be installed depends on the volume of the cooling chamber. The sensor device can be effectively divided into zones, according to areas in controlled temperature spaces that are affected by similar influences. If the monitoring devices are zoned, the operating data can be compared to provide a picture of the overall functioning of the system.

At present, there are many studies focused on studying and controlling indoor storage temperatures. Different elevation temperatures used for storing the product for several weeks or months can cause losses in product qualities.

Reid and Perez [16] showed the influence of temperature fluctuations. Regular weighing of frozen gel (in the cold room) monitored the rate of moisture loss. In this way, the problems caused by condensation of absorbed moisture were minimized. The results clearly confirmed that the migration rate of moisture was increased at higher average storage temperatures. In addition, it was clearly evident that the migration rate of moisture was increased at higher fluctuations in temperature amplitude [16]. The signs of moisture migration occur mainly in frozen foods stored for a longer period of time.

In their studies, César Porras-Amores et al. [15] analyzed the vertical temperature gradients in the warehouses, quantified their value and analyzed their development during the year. The quality of a pharmaceutical product depends, to a large extent, on the environment during its storage and handling. Each pharmaceutical product should be handled and stored under the specified storage conditions listed on the product information sheet or in the product packaging. The temperature fluctuations during raw material intake, production of pharmaceutical products and distribution should be managed throughout the product life cycle [9].

Mercier et al. [4] showed that the cooling chain efficiency is not ideal. Often, temperature fluctuations occur above or below the optimum temperature range specific to the product. Temperature fluctuations threaten the safety of food and deteriorate it. They reviewed the studies of time and temperature conditions in each critical phase of the refrigeration chain to assess the current state of commercial refrigeration chains.

Some studies address the temperature control by using various control devices, i.e., microprocessors. The design of the microcontroller measurement system of storage temperature is found in the paper of Qi Bing Xia [19].
Innovative solutions are also available in this area. Xiao Feng Ning et al. [13] found that storing rice in winter in cold storage at low outside temperatures resulted in better germination, fewer changes in the physiological properties of the grain, and cracking of the core than under normal storage conditions. Temperature and relative humidity are the most important environmental factors affecting the sensory quality of products. Inappropriate storage conditions may cause undesirable physicochemical changes and loss of quality in the stored products. In addition, humidity and temperature may also affect the presence of insect pests $[13,2]$ which can damage the product.

In the paper of Campbell [2], the equations for determination of radiant heating and the time constant of small thermocouples used for measuring air temperature are given. The paper describes the study of temperature fluctuations using thermocouples.

A special regulator must be used to respond to temperature disturbances in and out of the chamber to ensure high temperature stability of the air in a constant temperature chamber. The effect of periodic variations of air temperature on the thermal stability of constant temperature chambers has been studied in the paper of Kazanskaya [6].

In this paper, daily measured temperatures in the cold store were evaluated. The data was compared with the outside air temperature. Various statistical tests were used to evaluate the measured data, i.e., Kruskal-Wallis test, Bartlett's test, and Nemenyi test.

The Kruskal-Wallis test is a nonparametric (distribution free) test and is used when the assumptions of one-way ANOVA are not met. Both the Kruskal-Wallis test and one-way ANOVA assess for significant differences on a continuous dependent variable by a categorical independent variable (with two or more groups). The KruskalWallis test by ranks, Kruskal-Wallis $\mathrm{H}$ test [7] (named after William Kruskal and W. Allen Wallis), or one-way ANOVA on ranks [7] is a nonparametric method for testing whether samples originate from the same distribution $[8,3,17]$. It is used for comparing two or more independent samples of equal or different sample sizes. It extends the Mann-Whitney $U$ test when there are only two groups. The parametric equivalent of the Kruskal-Wallis test is the one-way analysis of variance. A significant Kruskal-Wallis test indicates that at least one sample dominates stochastically over other samples. The test does not identify where this stochastic dominance occurs 
or for how many pairs of groups stochastic dominance obtains.

Since it is a non-parametric method, the Kruskal-Wallis test does not assume a normal distribution of the residuals, unlike the analogous one-way analysis of variance. If a researcher can make less stringent assumptions of an identically shaped and scaled distribution for all groups, except for any difference in medians, then the null hypothesis is that the medians of all groups are equal, and the alternative hypothesis is that at least one population median of one group is different from the population median of at least one other group.

In statistics, Bartlett's test [18] is used to check if the $\mathrm{k}$ samples are from the populations with equal variances. Equal variances across populations are called homoscedasticity or homogeneity of variances. Some statistical tests, for example, the analysis of variance, assume that variances are equal across groups or samples. The Bartlett test can be used to verify that assumption.

Bartlett's test is sensitive to departures from normality. That is, if the samples come from nonnormal distributions, then Bartlett's test may simply be testing for non-normality. Levene's test and the Brown-Forsythe test are alternatives to the Bartlett test that are less sensitive to the departures from normality [14, 4].

In statistics, the Nemenyi test is a post-hoc test intended to find the groups of data that differ after a statistical test of multiple comparisons (such as the Friedman test) has rejected the null hypothesis that the performance of the comparisons on the groups of data is similar. The test makes pair-wise tests of performance. The test is named after Peter Nemenyi [12]. The test is sometimes referred to as the "Nemenyi-DamicoWolfe-Dunn test" [17].

The paper consists of several parts. The "Material and Methods" section describes the refrigeration store and the principle of its operation. The "Theory/calculation" section includes a statistical analysis of the data obtained. The next section analyzes the causes of the found problem, i.e., non-compliance or fluctuations in temperatures set in the warehouse. Finally, corrective actions are proposed to eliminate the problem.

\section{MATERIAL AND METHODS}

The refrigeration (cooling) store is an area for storing foodstuffs perishable due to a higher temperature than the set storage temperature with respect to the requirement to maintain its quality.

Product warehouses must be equipped with measuring, regulation and recording devices enabling the compliance with and control of the specified storage conditions.

The stored products and packaging must be stored in such a way to be safely accessible; may not be stored directly on the floor nor touch the walls.

Figure 1 shows a diagram of a cold store with a description of its essential parts. The compressor is the heart of the cooling system. The compressor compresses the cooling medium in the gaseous state, increases its pressure and

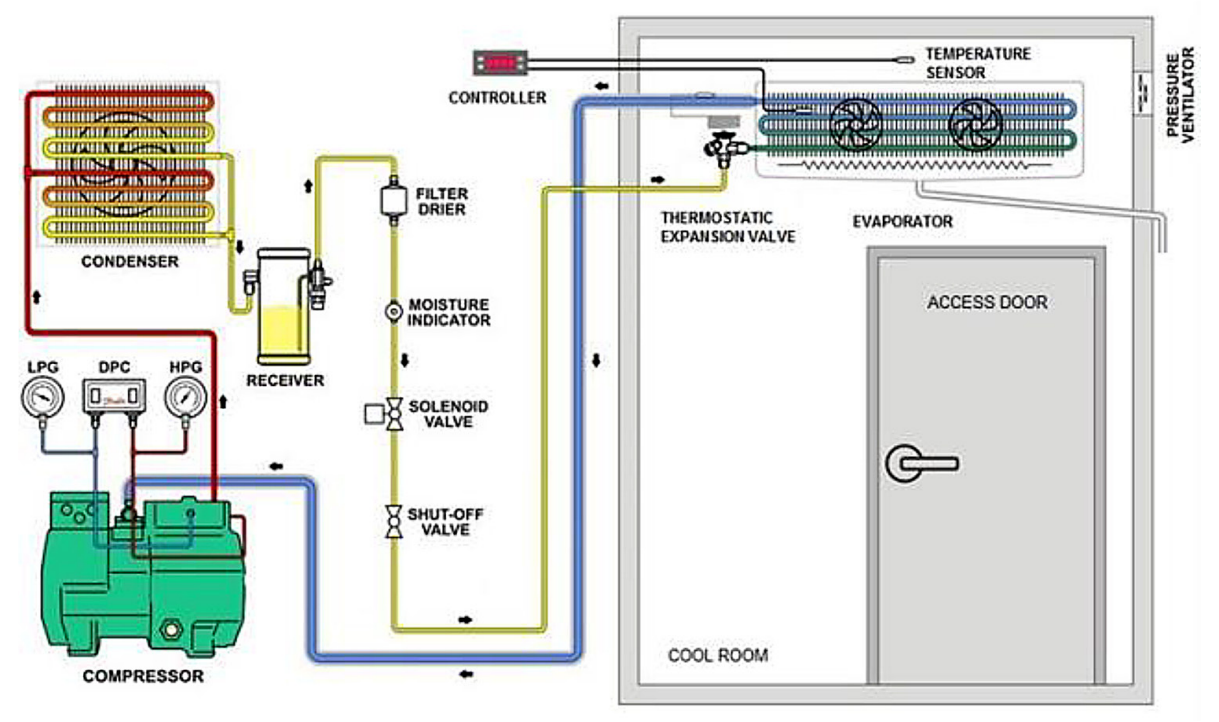

Fig. 1. Cold storage refrigeration system piping diagram. 
temperature as well as pushes it into the condenser. The condenser is a heat exchanger where gas is cooled and changed to liquid. When condensing the steam into the liquid, the steam must pass a portion of internal energy (so-called condensation heat) to the environment. Heat is fed by the fan. The liquid coolant passes through the expansion valve, where the pressure drops sharply. The refrigerant enters the evaporator as a cold, low pressure liquid; the refrigerant begins to boil and evaporate, the evaporation causes a cooling effect in the room. The refrigerant leaves the evaporator as a warm, saturated low pressure gas. The circulation is closed and repeated periodically.

The air temperature monitoring is designed to indicate the operation of refrigeration equipment, while the air temperature does not need to correspond to the temperature of the food. However, the air temperature records are an important indicator when assessing the suitability of the relevant refrigeration equipment.

In-store temperature sensors should be conveniently positioned to measure the temperature at the warmest place. The measurement accuracy must be ensured by proper calibration. The sensors should be located as high as possible, far enough away from the evaporator fan and at a sufficient distance from the inlet and outlet doors, to avoid sensing of too low temperatures or sporadic temperature fluctuations. The simplest way to monitor temperature is to read the mechanical thermometer data regularly and manually record it in the appropriate written form.

The number of temperature sensors depends on the size of the cool storage. Only one sensor can be used in a store smaller than $500 \mathrm{~m}^{2}$ (our case).

However, electronic thermometers are more commonly used to monitor the air temperature. They consist of a sensor located in the refrigerating compartment and reading and/ or recording device. Recording equipment is most often an analogue or mechanical recorder with graphical recording on special paper. An advantage is a simple check of the recorded data.

Figure 2 shows a process for evaluating measured data in a refrigeration store:

1. A daily record of temperatures in the cold store for 12 months.

2. Analysis of the applied statistical methods (statistical analysis of temperatures) - in this step the obtained data of temperatures measured in the cold store were statistically evaluated.
a) Assessment of temperatures using

descriptive statistics - In this step, all the measured data are evaluated using descriptive statistics.

b) Assessment of temperatures in individual months - the measured data are evaluated, and the graph is displayed by each month.

c) Comparison of temperatures and group formation - the measured data in individual months are compared to each other and groups of similar months are formed.

d) Monitoring of dependence between store temperatures and outside air temperature, i.e., the measured air temperature values in the store are compared with the outside air temperature. The dependence between data is checked.

e) Conclusions from the statistical survey.

3. Analysis of causes of temperature fluctuations. Brainstorming determines the causes of temperature fluctuations in the store. Dependence and relationship between the causes are identified.

4. A suggestion of corrective actions to reduce temperature fluctuations in the cold store.

\section{THEORY/CALCULATION}

\section{Daily temperature recording in cold store}

When storing the foodstuffs perishable due to temperature, there is a legal requirement to measure the air temperature in the cool store once a day. The data recorded for a period of 12 months, representing the entire calendar year are analyzed.

Due to the stored product range, the range of air temperatures in the store is set from $+1^{\circ} \mathrm{C}$ to $+5^{\circ} \mathrm{C}$.

On the basis of these requirements, an optimal average temperature of $+3^{\circ} \mathrm{C}$ was determined. It is advisable for the measured temperatures to have a normal distribution with this mean value and a standard deviation of up to $2 / 3$, i.e., 0.67 . This requirement also arises from the density of probability of normal distribution.

The recorded measurement results were analyzed for each calendar month.

The data analysis consists of evaluating the measured data using descriptive statistics, monthly comparison in terms of measured values, examining the relationship between outside temperature and storage temperature. 


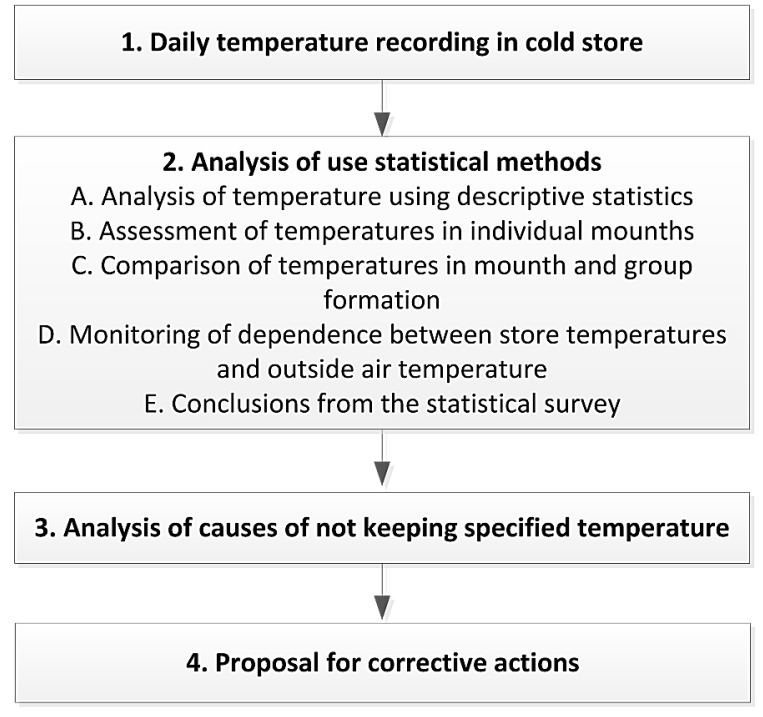

Fig. 2. The sequence of the cold storage temperature evaluation steps

\section{Analysis of use statistical methods}

a) Analysis of temperature in store using descriptive statistics:

Descriptive statistics of measured storage temperatures over the whole reference period are shown in Table 1.

Table 1 shows that the specified temperature interval has not been met. The measured air temperature in the store was higher than the upper standard limit (USL $=+5^{\circ} \mathrm{C}$ ) and 7 times lower than the lower standard limit $\left(\mathrm{LSL}=+1^{\circ} \mathrm{C}\right)$. The calculated average air temperature in the storage is satisfactory. The standard deviation of 0.96 is higher than the optimal value of 0.67 . The data do not come from a normally divided population, the value of the p-value of Shapiro-Wilkov's normality test $<0.05$.

Table 1. Descriptive statistics of measured storage temperatures

\begin{tabular}{|l|c|}
\hline \multicolumn{1}{|c|}{ Description } & Value \\
\hline Count & 359 \\
\hline Min & 0.5 \\
\hline Max & 5.1 \\
\hline Range - R & 4.6 \\
\hline Average & 3.17 \\
\hline Standard deviation $-s_{d}$ & 0.96 \\
\hline Shapiro-wilk normality test p-value & $4.6 \mathrm{E}-05$ \\
\hline Count values below LSL & 7 \\
\hline Count values above USL & 1 \\
\hline
\end{tabular}

b) Assessment of temperatures in store in individual months:

The calculated descriptive statistics for individual months are shown in Table 2. Graphically, the results of the measurements are presented in the box graph (see Figure 3). The boxes present the mean value and variability of the measured temperatures in each month. The LSL line (Lower Standard Line) represents the lower tolerance, and the USL line (Upper Standard Line) is the upper limit of the specified temperature range. On the basis of Figure 3 and Table 2 it is obvious that:

- In four consecutive months, i.e. January, February, March, April, the lower temperature limit $+1{ }^{\circ} \mathrm{C}$ was exceeded. In January, the minimum allowed temperature was exceeded three times, in April - twice, in February and March - once. The lowest recorded temperature was $-0.5^{\circ} \mathrm{C}$ in April.

- In March, July and August the temperature was around the upper limit of USL $=+5^{\circ} \mathrm{C}$. In June, the maximum allowed the temperature of $+0.1^{\circ} \mathrm{C}$ was exceeded in the store.

- Figure 3 and Table 2 exhibit large variability of the measurement results through Range $\mathrm{R}$ in January, February, March, and April.

- The results of verifying the normality of measured data indicate that the population of the results from the measurements can be considered a normal distribution in March, April, July, September, November, and December. In the remaining months, the hypothesis about the normal distribution of the population is rejected. This means that data are not bundled around the average.

The critical months are:

- January to April - winter months, due to exceeding the lower temperature limit (LSL) and high variability. In these months, the standard deviation was higher than the established maximum standard deviation.

- June to August - summer months; in these months, the average temperature was $+1{ }^{\circ} \mathrm{C}$ higher than the optimal value. The standard deviation value in these months was satisfactory.

c) Comparison of temperatures in months and group formation:

A Kruskal-Wallis test was chosen to verify the existence of statistically significant differences between storage temperatures in individual months. The test was selected on the basis that the 
Table 2. Descriptive statistics of storage temperatures in individual months

\begin{tabular}{|c|c|c|c|c|c|c|c|c|}
\hline & Min & Max & Range & Average & $\begin{array}{c}\text { Standard deviation } \\
\mathrm{s}_{d}\end{array}$ & p-value & Below LSL & $\begin{array}{c}\text { Above } \\
\text { USL }\end{array}$ \\
\hline Jan & 0.8 & 3.9 & 3.1 & 1.92 & 0.8 & 0.04 & 3 & 0 \\
\hline Feb & 0.8 & 4.5 & 3.7 & 2.38 & 1.6 & 0.04 & 1 & 0 \\
\hline Mar & 0.8 & 5 & 4.2 & 2.72 & 1.4 & 0.23 & 1 & 0 \\
\hline Apr & 0.5 & 4.3 & 3.8 & 2.6 & 1 & 0.48 & 2 & 0 \\
\hline May & 2.7 & 4.7 & 2 & 3.39 & 0.47 & 0.03 & 0 & 0 \\
\hline June & 3.1 & 5.1 & 2 & 3.96 & 0.53 & 0.03 & 0 & 1 \\
\hline July & 2.5 & 5 & 2.5 & 3.97 & 0.56 & 0.32 & 0 & 0 \\
\hline Aug & 3.1 & 5 & 1.9 & 4.37 & 0.56 & 0.01 & 0 & 0 \\
\hline Sept & 2.5 & 4.5 & 2 & 3.28 & 0.46 & 0.17 & 0 & 0 \\
\hline Oct & 2.3 & 4.8 & 2.5 & 3.2 & 0.49 & 0.01 & 0 & 0 \\
\hline Nov & 2.1 & 4 & 1.9 & 3.3 & 0.39 & 0.16 & 0 & 0 \\
\hline Dec & 2.3 & 3.8 & 1.5 & 3.1 & 0.31 & 0.68 & 0 & 0 \\
\hline
\end{tabular}

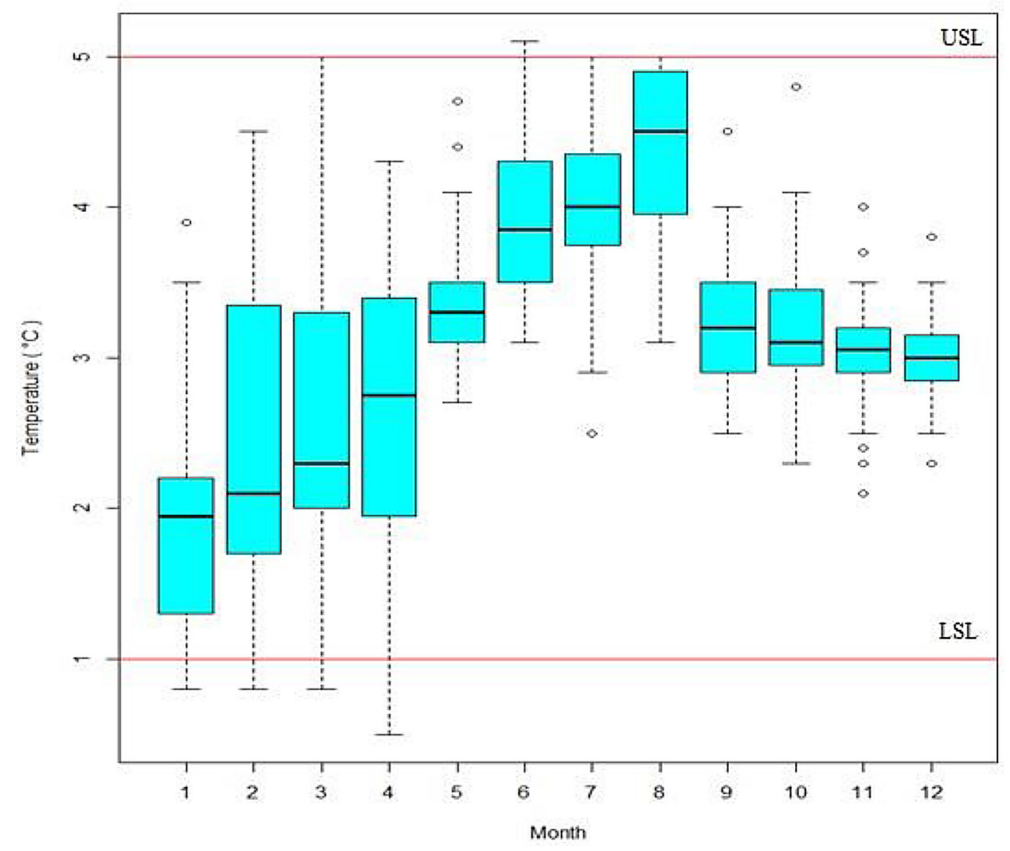

Fig. 3. The recorded temperature in cold store of finished products

assumptions for the use of parametric assays were not met; the data did not have normal population distribution and homoscedasticity.

Homoscedasticity (homogeneity of variances) of the population was confirmed by Bartlett's test of homogeneity of variances with the result of $\mathrm{p}$-value $=2.42 \mathrm{e}-16$. This means that the zero hypotheses of dispersion homogeneity are rejected.

The result of comparing the air temperature in the store by individual month, by Kruskal-Wallis rank sum test is the p-value of 2.2e-16. This means that there are at least two months in which temperatures are statistically significantly different from each other. In order to find similar and different months, the paired comparison was used according to Nemenyi's test of multiple comparisons for independent samples.

The results of pair comparisons between the average temperatures in the month, for which the zero matching hypothesis was rejected, are shown in Table 3. These results coincide with the graphical comparison of the groups in the box graph (see Figure 3).

On the basis of results (Table 2 and Table 3), three groups of months were created for which the zero hypothesis of compliance was not rejected. Time series of daily temperatures were presented graphically for each group of months together with the determined optimal average temperature and the USL and LSL limits: 
Table 3. Results of Nemenyi's test

\begin{tabular}{|c|c|c|c|c|c|}
\hline Month & mean. rank. differentia & $\mathrm{p}$ - value & Month & mean. rank. differentia & $\mathrm{p}$ - value \\
\hline aug-apr & 186.8531 & $3.3 \mathrm{e}-10$ & may-feb & 96.80990783 & 0.01799 \\
\hline july-apr & 151.8531 & $1.3 \mathrm{e}-06$ & july-jan & 214.42096774 & $2.0 \mathrm{e}-13$ \\
\hline june-apr & 151.8988 & $1.7 \mathrm{e}-06$ & june-jan & 214.46666667 & $2.4 \mathrm{e}-13$ \\
\hline dec-aug & -165.6210 & $6.1 \mathrm{e}-08$ & may-jan & 142.32419355 & $5.6 \mathrm{e}-06$ \\
\hline feb-aug & -203.9067 & $3.3 \mathrm{e}-12$ & nov-jan & 91.61666667 & 0.03089 \\
\hline jan-aug & -249.4210 & $1.1 \mathrm{e}-13$ & oct-jan & 112.72741935 & 0.00134 \\
\hline may-aug & -107.0968 & 0.00283 & sep-jan & 125.78333333 & 0.00017 \\
\hline mar-aug & -180.8871 & $4.5 \mathrm{e}-10$ & mar-july & -145.88709677 & $2.0 \mathrm{e}-06$ \\
\hline nov-aug & -157.8043 & $1.9 \mathrm{e}-07$ & nov-july & -122.80430108 & 0.00024 \\
\hline oct-aug & -136.6935 & $1.4 \mathrm{e}-05$ & oct-july & -101.69354839 & 0.00642 \\
\hline sept-aug & -123.6376 & 0.00021 & sep-july & -88.63763441 & 0.04055 \\
\hline july-dec & 130.6210 & $8.8 \mathrm{e}-05$ & mar-june & -145.93279570 & $2.6 \mathrm{e}-06$ \\
\hline june-dec & 130.6667 & 0.00011 & nov-june & -122.85000000 & 0.00028 \\
\hline july-feb & 168.9067 & $2.8 \mathrm{e}-08$ & oct-june & -101.73924731 & 0.00720 \\
\hline june-feb & 168.9524 & $3.8 \mathrm{e}-08$ & sep-june & -88.68333333 & 0.04393 \\
\hline
\end{tabular}

- group of summer months - June, July, and August (see Figure 4),

- group of autumn months - September, October, November, December (see Figure 5),

- group of winter months - January, February, March, and April (Figure 6).

The rule for grouping is as follows:

- In pair comparison, a zero matching hypothesis was not rejected for any two months in the same group.

- There is more than one pair of months of the first and the second groups, the second and the third groups and the first and the third groups for which the zero matching hypothesis was rejected in the paired comparison.

Figure 4 shows that in the summer months, the temperature in the store is in the upper tolerance zone above the Central Line $(\mathrm{CL})+3^{\circ} \mathrm{C}$. The lowest value was recorded in July and reached $2.5^{\circ} \mathrm{C}$.

Figure 5 indicates that in the autumn months, the temperatures in the store oscillate around $\mathrm{CL}$
$+3{ }^{\circ} \mathrm{C}$. The first recorded temperature in October reaches the highest value of the selected group, i.e. $4.8^{\circ} \mathrm{C}$.

Figure 6 shows that in the group of winter months, the measured temperature dropped below the set minimum value $+1{ }^{\circ} \mathrm{C}$. Most of the measured values oscillate below $\mathrm{CL}+3{ }^{\circ} \mathrm{C}$. In March, the values were the highest ones. One value reached the set maximum value of $+5{ }^{\circ} \mathrm{C}$. May cannot be classified into any of the groups, based on the measured temperature results.

d) Monitoring of dependence between cold store temperatures and outside air temperature:

The data was cleared of the trend component to analyze the relationship between the outside average air temperature and the store air temperature. For external temperatures, the trend was considered in the shape of the third degree polynomial. A constant trend of $+3{ }^{\circ} \mathrm{C}$ was considered for storage temperature, i.e. the optimal

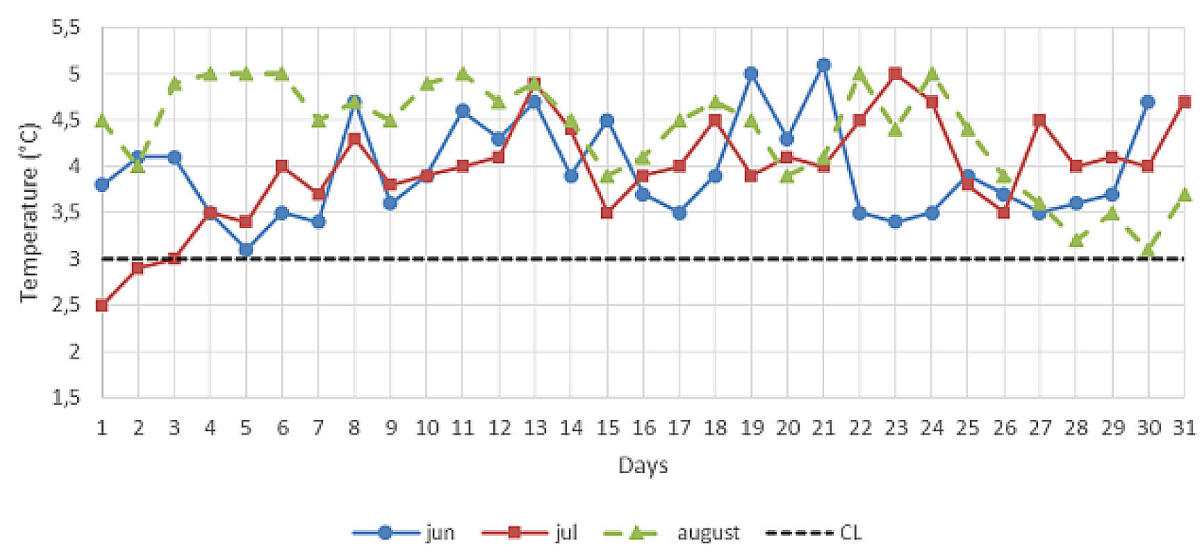

Fig. 4. Recorded temperature in cold store in the group of summer months 


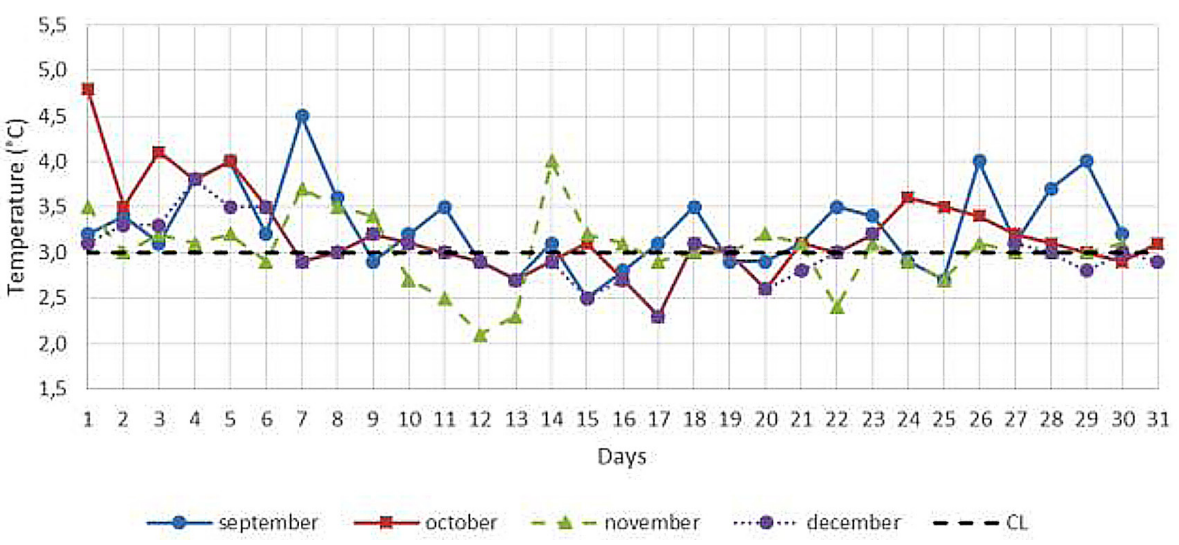

Fig. 5. Recorded temperature in cold store in the group of autumn months

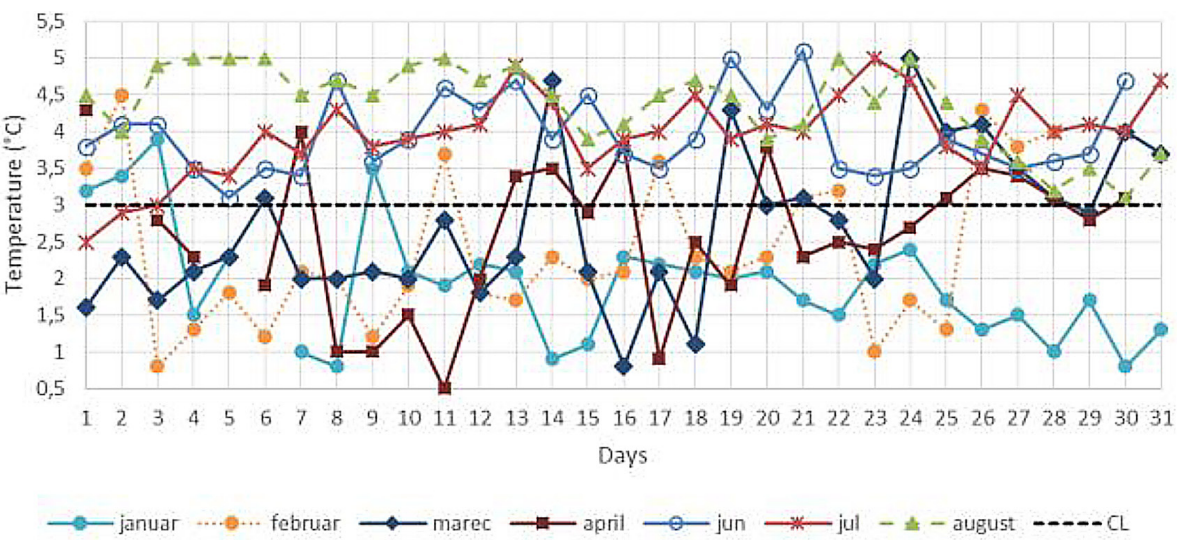

Fig. 6. Recorded temperature in cold store in a group of winter months

average value. The calculated Pearson correlation coefficient " $r$ " is 0.256 , indicating that there is a relationship between store temperatures and an outside average daily temperature with a p-value of $8.7 \mathrm{e}-07$.

A constant trend with the arithmetic mean of the temperature in the month is predicted for the temperature in the store to find out the correlation between the temperature in the store and the outside temperature for each month. The results of the correlation between the average outside temperature and the storage temperature are shown in Table 4 . The statistically significant correlation was confirmed in March, May, and November (highlighted).

Figure 7 shows two time series of deviations from the trend in these months (March, May, November) - the time series of the outside temperatures and the time series of the storage temperatures, both of them being cleared of the trend component.

e) Conclusions from the statistical survey:

In the winter months, the measured temperature dropped below the set value. In these months, the variability of the measured values was high. This indicates that there are no appropriate mode arrangements to keep the air temperature in the store and outside space, or they have not been observed or specified. In the summer months, the average measured storage temperature was in the upper tolerance band, and the measured data had low variability. This indicates that insufficient cooling performance has been set. For three of twelve months analyzed, there was a proof for the existence of the linear relationship between the outside air temperature and the air temperature in the cold store. Measurements were performed

Table 4. Correlation values between storage temperature and outside temperature

\begin{tabular}{|c|c|c|c|c|c|c|c|c|c|c|c|}
\hline Jan & Feb & March & April & May & Jun & July & Aug & Sep & Oct & Nov & Dec \\
\hline 0.234 & -0.261 & 0.375 & 0.172 & 0.359 & 0.204 & 0.082 & -0.008 & -0.055 & 0.073 & 0.396 & 0.253 \\
\hline
\end{tabular}



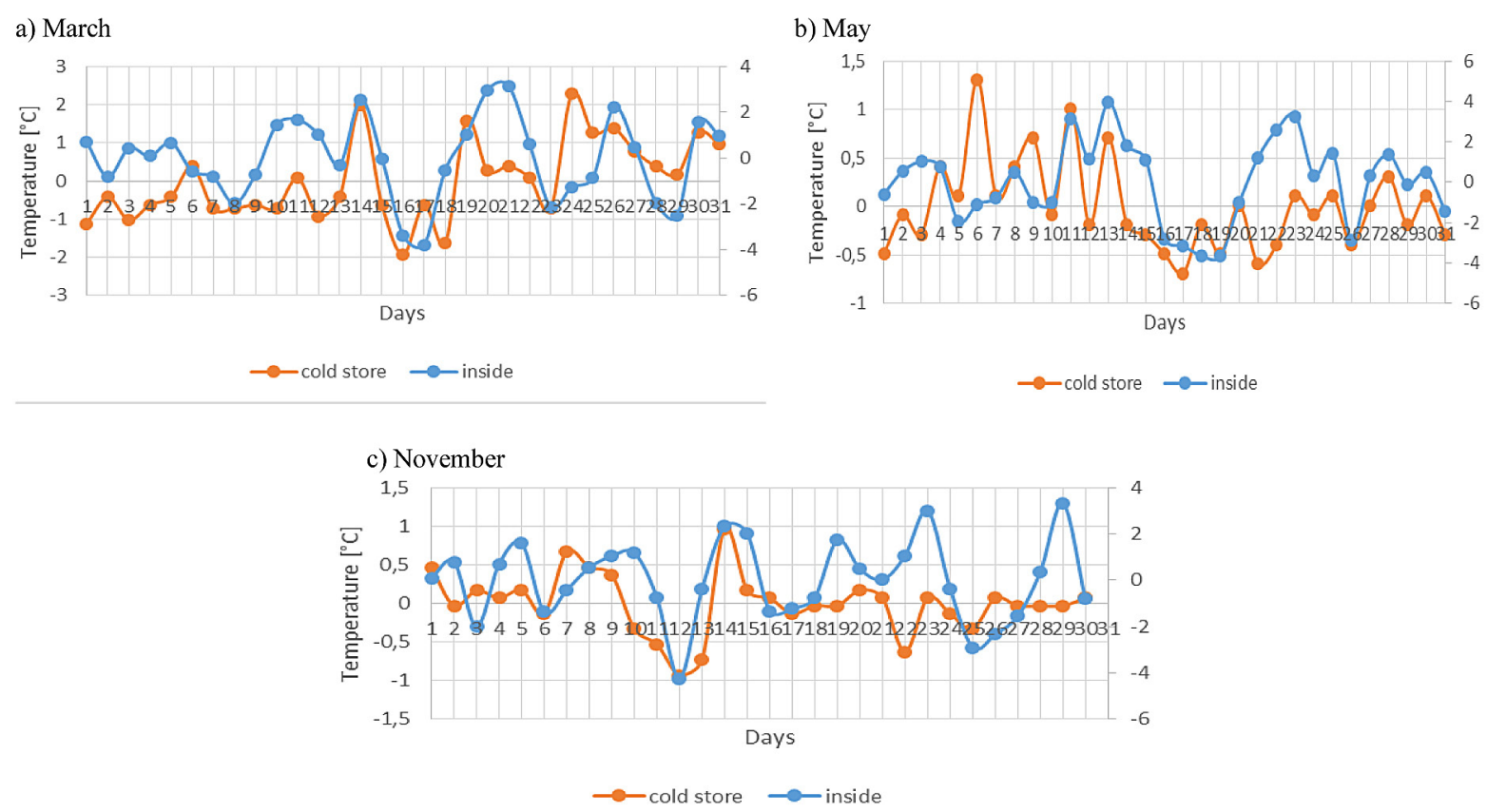

Fig. 7. Time trend of storage temperatures an outside temperature in individual months

once a day; there is a possibility that the temperature in the store could have actually even exceeded the tolerance values in the short term.

\section{Analysis of causes of not keeping the specified temperature}

The purpose of the analysis is to identify the causes of not keeping, fluctuation of the set temperature in the cold store, their relations, and importance. The failure to keep the set temperature will be called the effect. The next objective is based on findings to suggest the measures to remedy the effect.

A Cause-Effect diagram or an Ishikawa diagram was used to solve the problem. This diagram has the shape of a fish bone (see Figure 8). On the right side of the diagram, there is an effect - the head of the fish bone. The left-hand side of the diagram shows the causes. Major cause categories are shown as gross fish bones. Subcategories of causes are secondary causes [1].

The following categories of causes which cause temperature fluctuations in the cold store (see Figure 8) were identified through brainstorming - human factor, products, temperature measurement, thermoregulation, weather effects, component failure, power outages.

the statistical quality tools i.e. Relations diagram were used, to identify the relationship between the main causes. This diagram [11] is also referred to as Interrelationship Digraph. It allows identifying logical or causal links between different categories of causes that relate to the problem being solved. The relational diagram shown in Figure 9 was created to determine the relationship between causes and effects,.

While determining the relations, the answer to the question: "Can this factor affect another?", is sought. While creating a relational diagram, the logical and causal relationship is shown by the arrows leading from the cause to the effect. This process was repeated for all causes. After plotting the diagram, the number of inputs and outputs was calculated. The order of the individual categories of causes was determined. However, the resulting relations do not imply the importance of the cause, just mutual dependence.

The relational diagram Figure 9 showed that it is not uniquely identified by the key causes of temperature fluctuations in the cold store. The temperature fluctuations are affected mainly by three categories of causes - human factor, component failure, and weather effects. Each of these cause categories has four outputs.

The human factor is one of the causes significantly influencing temperature fluctuations in the finished product store. This category of causes affects:

- Products - quantity and location of the products deposited. Some products in the production process undergo certain heat treatment. When placed in a cold store, they must have an optimal temperature. 


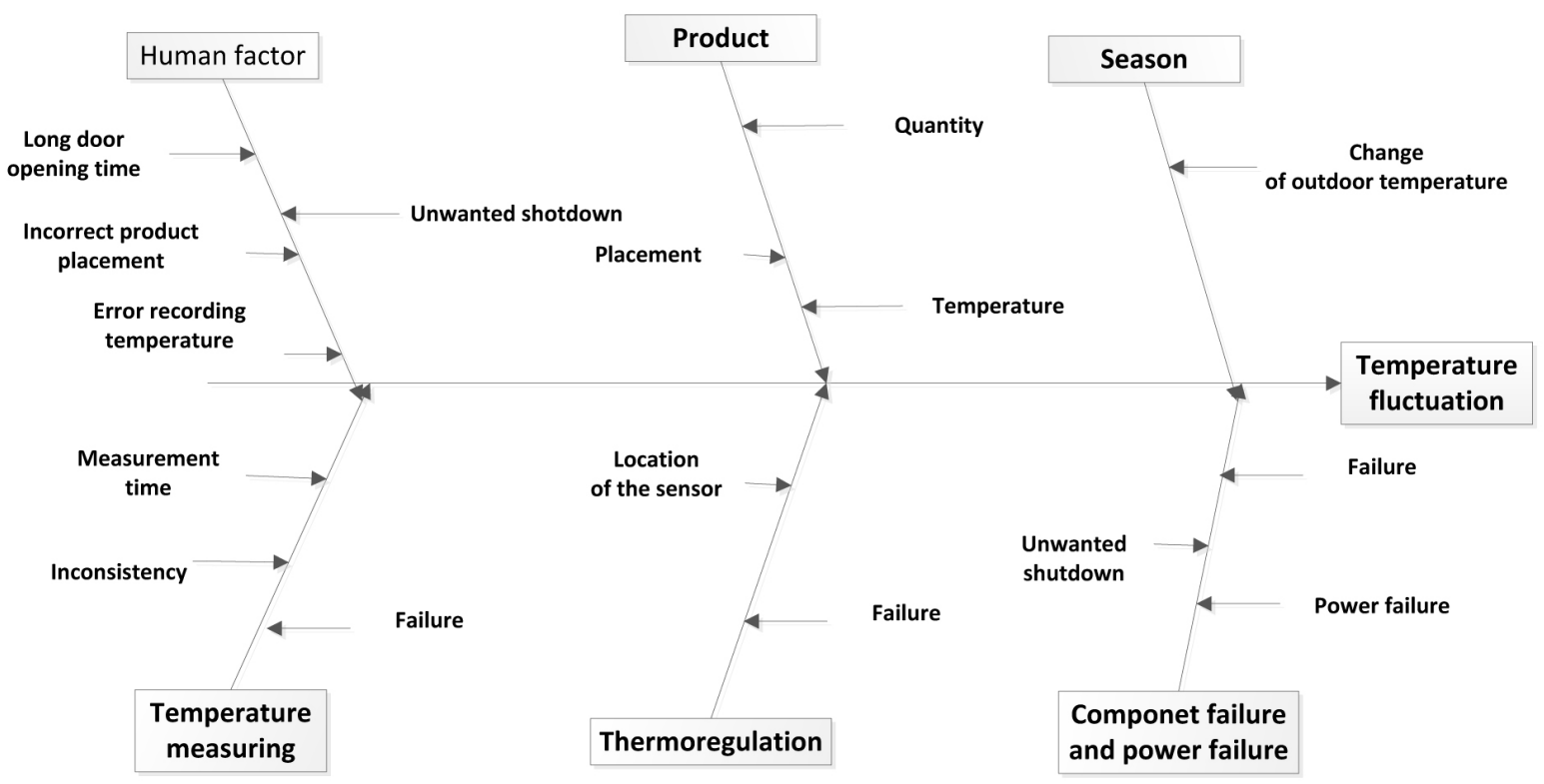

Fig. 8. Cause-Effect diagram.

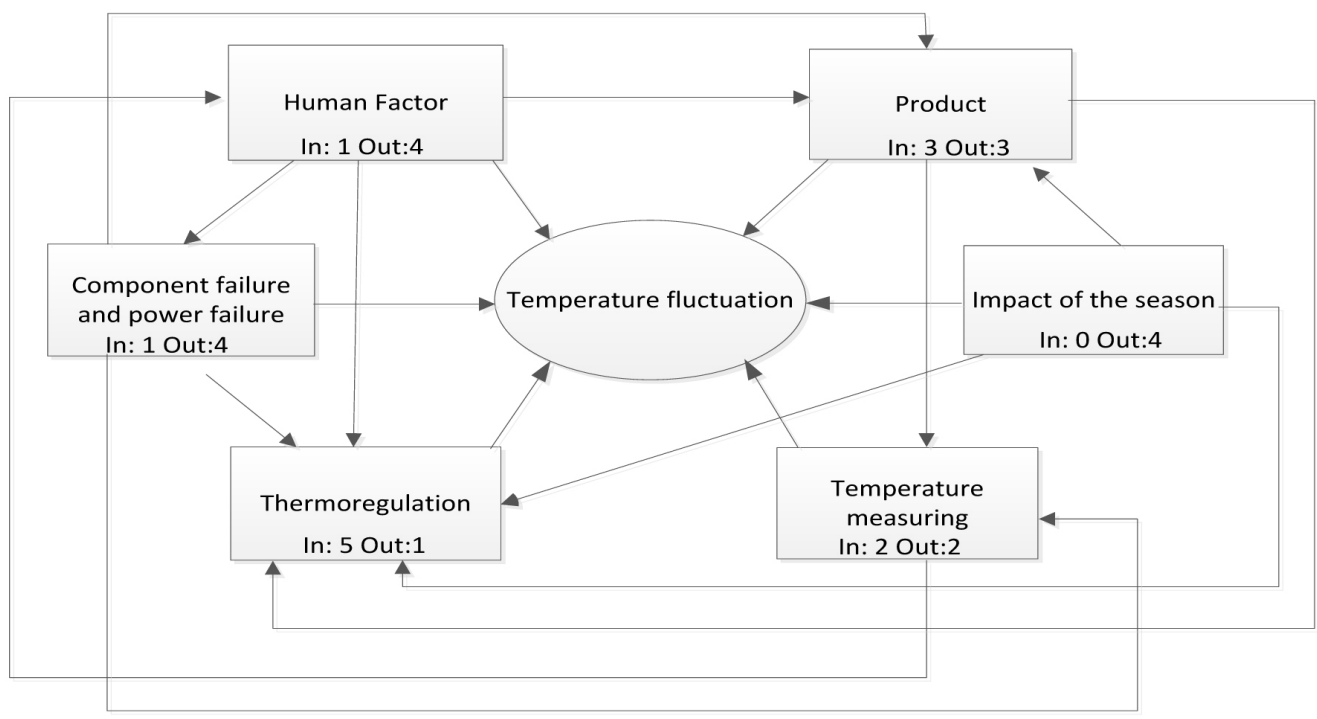

Fig. 9. Relations diagram

- Setting the thermoregulation.

- Serviceability of components and unintentional disconnection of power supply.

Device component failure and the power failure may occur sporadically. This factor is risk. Component failure or power failure affects:

- thermoregulation,

- temperature reading,

- products because of their degradation.

The impact of the weather was also confirmed by statistical surveys. The changes in temperature during the seasons affect:

- thermoregulation system - works differently in winter and in the summer months,
- measured temperature,

- products temperature, as temperatures fluctuate. The cold store is located directly at the distribution point. When unloading, it is open and thus comes into contact with ambient air, and seasonally it affects the temperature in the store.

Products - less significant factor (3 outputs) influencing the temperature fluctuations in the store. The quantity, temperature, and method of products storage affect:

- thermoregulation;

- measured temperature. 
Thermoregulation affects the measured values of temperature and products. Incorrect setting of thermoregulation or its failure may have serious consequences. It is important to place the thermostatic sensor properly, as described in the introduction to the paper.

The measured temperature is influenced by the human factor. Incorrect temperature readout (incorrect entry or readout time) can lead to incorrect thermoregulation setting. The measurement results are different after distribution than those at reading the temperature after a certain time period has elapsed when the temperature in the store has stabilized.

\section{RESULTS AND DISCUSSION}

The statistical analysis showed that temperature fluctuations occur in the cold store. During the winter months, the measured temperature dropped below the set value which can cause:

- degradation of foodstuff,

- reduction of the biological value of the products,

- loss of original properties - taste, color, smell, etc.

In the summer months, the average storage temperature measured in the upper tolerance band. Higher temperatures can cause the occurrence of microorganisms in products. Three months (March, May, and November) confirmed the linear dependence of the temperatures measured in the cold store with the outside air temperature.

The C-E diagnostics, Relation diagram and brainstorming tools, were used to solve the problem of temperature fluctuations in the cold store. On the basis of the analysis, corrective actions were proposed:

- It is necessary to minimize or to eliminate the effect of the season on the storage temperature. By introducing the guards/ curtains. There will be less heat exchange between the cooling box and the surrounding area of the product distribution. These curtains serve as a dividing wall. They can be lifted or shifted. They allow free movement or passage of vehicles. In addition to the elimination of heat exchange, their purpose is also to reduce the electricity consumption and protect the store against dust particles.
- In order to increase the credibility of the human factor, it is necessary to develop rules (standards) and to ensure that they are adhered to. The proposed standards related to products and temperature measurements. The proposed standards are in Table 5. The standards should be reviewed and approved. They must be available and suitable for use.

- The other proposed measures concern the human factor. It is necessary to provide training for the workers who come into contact with cooling boxes and refrigerators. The aim of the training is to inform the workers about:

o optimal time of door opening,

o correct temperature of placing the products that undergo a certain heat treatment,

o optimal quantity of placed products,

o the correct time of reading out and recording the temperature.

- Training at the workplace can take place in the form of:

o working meetings - meetings to communicate, coordinate and improve the work performance;

o mentoring - it is an informal method of education. The trained worker is assigned a mentor who acts as a helper and a guide and provides feedback to the trainee.

o graphical form via instruction posters, pictograms.

- In order to ensure the optimum functioning of the cooling system, it is necessary:

o to define correct requirements for appliances according to the type of use;

o to use equipment from renowned manufacturers;

o to ensure its correct installation.

o Even the use of high quality equipment without regular inspection, service, and maintenance will not ensure reliable and trouble-free operation.

Table 5 Proposed rules / standards

\begin{tabular}{|l|l|}
\hline Rules/ Standards for: \\
\hline Products & $\begin{array}{l}\text { - depositing/taking foodstuff from the store } \\
\text { (first in/ first out) } \\
\text { - storing products } \\
\text { - determination of the temperature of } \\
\text { products placed according to HACCP } \\
\text { principles }\end{array}$ \\
\hline Temperature & $\begin{array}{l}\text { - temperature measuring } \\
\text { - temperature setting }\end{array}$ \\
\hline
\end{tabular}


- In order to increase the reliability of the measurement and to eliminate the thermoregulation errors, it is necessary to consider the redundancy $\mathrm{N}+1$, or $2 \mathrm{~N}$. Redundancy would involve thermos-sensors, but also a readout device - a thermometer. Redundancy of power supply should also be considered.

- We propose using an automated system for measuring and controlling the temperature with recording in the database by continuous evaluation of ambient conditions or influencing factors and gradual adaptation of control.

\section{CONCLUSIONS}

Food storage temperature is one of the most important factors influencing its quality. In the cold store, temperature fluctuations often occur above or below the optimum temperature range. Increasing temperatures in the cold store create favorable conditions for the formation of microorganisms. Food can be degraded when the temperature is lower than the specified one.

The paper analyzed the influence of outside air temperature on the temperature in the cold store. The temperatures were monitored throughout the year. The statistical analysis of the measured temperatures in the cold store revealed that the season period or the temperature changes in the seasons affect the temperature in the store. Using the quality tools, the key factors influencing the temperature changes in the store were identified. Corrective actions concerning not only the staff but also the technical equipment of the workplace were suggested based on this analysis. The suggested measures concerning the staff include the development of workflows for the product, procedures for correct temperature measurement and training of staff. The measures concerning the technical equipment should minimize temperature fluctuations and increase the operational reliability.

The next step should involve implementing these measures into practice and evaluating their effectiveness.

\section{Acknowledgments}

This work was supported by the Slovak Grant Agency for Science under grant VEGA 1/0273/17.

\section{REFERENCES}

1. Dale, B.G. et al. Managing Quality. Wiley-Blackwell, 5th ed, 2007, 357-359.

2. Campbell, G.S. Measurement of air temperature fluctuations with thermocouples, Report, Defense Technical Information Center, 1969. doi: https:// doi.org/10.21236/ad0697107

3. Corder, G.W., Foreman, D.I. Nonparametric Statistics for Non-Statisticians. Hoboken: John Wiley \& Sons, 2009, 99-105.

4. Gunst, F.R., Hess, J.: Statistical design and analysis of experiments: with applications to engineering and science. Wiley. pp. 98.

5. Hollander, M., Wolfe, D.A. Chicken E. Nonparametric Statistical Methods. Wiley, Chichester, (3nd ed.), 2013.

6. Kazanskaya, T. L. Effect of periodical air temperature fluctuations on thermal stability of constanttemperature chambers, Measurement Techniques, 16(3), 1973, 387-389. doi: https://doi.org/10.1007/ bf00812736

7. Kruskal, W.H., Wallis, W.A. Use of ranks in onecriterion variance analysis. Journal of the American Statistical Association, 47(260), 1952, 583-621. doi: 10.1080/01621459.1952.10483441.

8. Kruskal, W.H. Test using SPSS Statistics, Laerd Statistics. URL: https://statistics.laerd.com/spsstutorials/kruskal-wallis-h-test-using-spss-statistics.php

9. Kumar, N., Jha, A. Temperature excursion management: A novel approach of quality system in pharmaceutical industry, Saudi Pharmaceutical Journal, 25(2), 2017, 176-183. doi: https://doi. org/10.1016/j.jsps.2016.07.001

10. Mercier, S., Villeneuve, S., Mondor, M., Uysal, I. Time-Temperature Management Along the Food Cold Chain: A Review of Recent Developments. In: Comprehensive Reviews in Food Science and Food Safety, 16(4), 2017, 647-667. doi: https:// doi.org/10.1111/1541-4337.12269

11. Nancy R. Tague's The Quality Toolbox, Second Edition, ASQ Quality Press, 2004, 444-446

12. Nemenyi, P.B. Distribution-free Multiple Comparisons. PhD thesis, Princeton University, 1963.

13. Ning, X.F., Li, H., Kang, T.H., Han, Ch.S. Storage Characteristics of Low Temperature Grain Warehouse using Ambient Cold Air in Winter, Journal of Biosystems Engineering, 37(3), 2012, 184-191. doi: https://doi.org/10.5307/jbe.2012.37.3.184

14. NIST/SEMATECH e-Handbook of Statistical Methods. Available online, URL: http://www.itl. nist.gov/div898/handbook/eda/section3/eda357. htm. Retrieved July 31, 2018. 
15. Porras-Amores, C., Mazarrón, F.R., Cañas, I. Study of the Vertical Distribution of Air Temperature in Warehouses, Energies, 7, 2014, 1193-1206. doi:10.3390/en7031193.

16. Reid, D.S., Perez A.L. The effect of average storage temperature, and temperature fluctuation on the rate of moisture migration in a model frozen food. 13th World Congress of Food Science \& Technology, IUFoST 2006, EDP Sciences, 2006. doi: 10.1051/IUFoST:20060151
17. Siegel, C. Nonparametric Statistics for the Behavioral Sciences (2nd ed.). New York: McGraw-Hill. 1988.

18. Snedecor, W.G., Cochran, W.G.A. Statistical Methods (8th ed.). Ames: Iowa. Blackwell Publishing Professional, 1989.

19. Xia, Q.B. The Food Warehouse Temperature Measurement System Design Based on Microcontroller, Applied Mechanics and Materials, Vol. 416-417, 2013,1043-1048, doi: https://doi.org/10.4028/ www.scientific.net/ AMM.416-417.1043. 